\title{
A taxonomic analysis proposal for research in Diplomatic Interpreting*
}

\author{
Catalina Iliescu Gheorghiu \\ University of Alicante
}

\begin{abstract}
This paper focuses on Diplomatic Interpreting (DI), a speciality often included either in the conference or dialogue interpreting branch, depending on geographic and modal variables. Historically, diplomatic interpreters resorted to bilateral interpreting or mediation, but in the modern day, they oscillate between short and full consecutive, and on occasion simultaneous (presidential press conferences). This diffuse affiliation and the relatively small job market niche - hence its absence from degree syllabi - might be two of the motives why DI has not captured more attention from scholars.

One interesting avenue for researchers might be the identification and classification of those aspects DI has in common with other types of interpreting, and what makes it different. In my discussion, I recapitulate DI specificities, encompassing requirements, expectations and devices, among which optimisation (as a strategy to overcome barriers and ensure full communication) is pivotal. As an illustration, I analyse an example of optimisation in the case of Romanian PM Viorica Dăncilă's political blunder on her first visit to Montenegro. Finally, I advocate the recognition of the specificity of DI and I call for focussed research in this area.
\end{abstract}

Keywords: diplomatic interpreting; optimisation; DI specificities; research in DI

\footnotetext{
* Iliescu Gheorghiu, Catalina. "A taxonomic analysis proposal for research in Diplomatic Interpreting". Across Languages and Cultures 21 (1) pp. 23-41 (2020) DOl: 10.15561084.2020.00002
} 


\section{TERMS, DEFINITIONS, OVERLAPS}

Although the role of diplomatic interpreters has been crucial throughout the evolution of human civilization, this activity has a relatively recent trajectory as a speciality in scholarly production. Mason (1999) had already noticed a lesser interest on behalf of academia in investigating business and diplomatic interpreting - unlike police, immigration or court interpreting, which seemed to have a "particularly sensitive and face threatening nature". According to Roda Roberts' classification (2002), which divided the field of interpreting into Conference, Court, and Community, Diplomatic Interpreting (DI) as such does not exist, but it is presumably implied either in the conference (Setton \& Dawrant 2016) or dialogue branches (Mason 1999), depending on the mode (bilateral, short or long consecutive, chuchotage, simultaneous - strongly criticised by Obst 2010) and the geographic area in which it is performed, see Martin (2003:428) on western vs eastern tradition of one or both directions.

Due to professional, academic and geopolitical reasons, the largest interpreting markets belonged to the industrialized countries and Conference Interpreting was the main or "almost exclusive" (Prunč 2012:3) concern of trainers and researchers in the $20^{\text {th }}$ century, with a spectacular evolution between the 1950s and the 1990s (Gile 2000). While Conference Interpreting is unequivocally labelled, Community Interpreting has followed an uneven terminological path (bilateral, liaison, ad-hoc, social, community, public service, cultural) and DI seems to share this fate. The implicit or explicit labelling denotes uncertainty in defining the discipline and its realm: DI referring either broadly to diplomacy and high-level meetings as in Kucerová (1990:37), who adopts the term from the Office of Language Services, U.S. Department of State and press conferences (Fu \& Chen 2019) or narrowly to translation and interpreting within a Diplomatic Mission - embassies, consulates as in Fuentes Luque (1999); Interpreting in Diplomatic Settings (more situational than the former) Buri (2015), Baranyai (2011). Other labels are: International Relations Interpreting (referring to supranational organizations) Reischlová (2012); Political Interpreting (referring mainly to international summits, also called summitry which seems to describe also the encounters between heads of state) Baigorri (2005); Brown (2008); Jiang (2013); Military Interpreting (referring to negotiations and treaties) Bowen \& Dobosz (1990); Takeda (2009) and/or War/Peace Interpreting (defining intermediation in conflict) Baker (2006, 2010); Escort Interpreting for Diplomats (referring to official visits) Weller (2004), or Executive Interpretation (conference interpreters accompanying political or business VIPs) as defined by Calliope ${ }^{1}$, an association recognised by AIIC; and Mediation in political settings Liao \& Pan (2018). 
I have opted for DI, as Setton \& Dawrant (2016) do, in its broadest sense, comprising both what Hankey (1946) called diplomacy by conference (referring to supranational bodies), and what Baigorri (2014) considered one-to-one diplomacy (between heads of state, ministers and the like), for two reasons: 1) because it is the most frequently used term in the literature I have reviewed; and 2) because I consider it comprehensive enough to cover the other labels and still delimit the activity and type of situations covered by this branch of the profession. Diplomatic interpreters are, according to Setton \& Dawrant (2016:32), conference interpreters with high performance standards, i.e. accredited freelancers employed by the National Ministry of Foreign Affairs, or in countries like China, civil servants who interpret for their own government, or a combination of both (Spain). Diplomats (with or without training as interpreters) undertake the task in some countries on a regular basis, as confirmed by a case study I conducted among Romanian Consulates in Spain. Heads of five of seven consulates answered my survey; all recognize the need and beneficial effect of a translator/interpreter, but only two consulates have hired one whereas three say the organigram only allows the recruitment of temporary collaborators (which occurs in one case). All stress that diplomats generally speak the language of the host country (especially international ones) and translate/interpret as a rule. In turn, Fuentes Luque (1999) shows that in Spain, of all the English-speaking embassies accredited, (except for the UK with an entire team of professionals) only Australia and USA have at least one translator/interpreter while the others draw on diplomats and administrative staff to carry out varied tasks: translation, interpreting (chuchotage, bilateral, simultaneous), documentation and consultancy. According to Setton \& Dawrant (2016:33) DI extends (in addition to formal consecutive or simultaneous at political talks, negotiations and press conferences) into dinners, receptions, ceremonies, tours and visits: "diplomatic interpreters can expect to interpret over the widest imaginable range of topics and settings, making use of informal 'short' consecutive, whispering as well as other kinds of mediation and diplomatic skills".

\section{SCHOLARLY NEGLECT}

In spite of its constant presence in international relations and prominent role in the making of history, there is still relatively little academic interest in systematic research into diplomatic interpreting. However, the motives for this low profile are not so surprising given the configuration of professional markets and training priorities. Thus, one possible reason is the fact that interpreting did not become a discipline for study until the twentieth century. Furthermore, while the first consecutive interpreters (at the Peace Conference in Paris in 
1919) and the first simultaneous interpreters (for the League of Nations and then the UN) performed DI, once the activity was professionalised, interpreters became everyday natural intermediaries at encounters and meetings of any kind and in any field. When the first "practisearchers" (Gile 2000) came onto the scene, they focussed on Conference Interpreting, the branch that seemed to provide regular employment (at least in the West).

Another reason might be the expansion of generalised training: the first training centres for interpreters appeared in the 1960s (Geneva, Paris, then Vienna, Trieste, Georgetown, Moscow, Prague), in the 1970s the first postgraduate programmes were introduced (ESIT), and then new chairs of T\&I (Germany, Finland) as well as faculties were set up. These developments produced a need for teaching materials, handbooks, and new insights. Since international conferences dealing with a wide range of topics and specialized areas were the most abundant job outlets for interpreters, they attracted the attention of scholars. Meanwhile, DI remained a fringe, mysterious branch of the profession. Universities trained conference interpreters, not diplomatic interpreters, a restricted job with few vacancies, often performed by diplomats themselves.

Thirdly, in the early days although the first supranational organizations such as the United Nations (UN) used mainly DI, the time for interventions was shorter, and meetings became more specialised as the number of member states grew (from 51 to 191) and as NGOs were included in debates. Thus, according to Baigorri (2004), the rhetorical style was replaced by speeches of high technicity delivered at great speed, especially since the end of the Cold War. This author shows (ibid) that the first generation of diplomatic interpreters performing erudite interventions was replaced by a second (more anonymous one) trained at specialised schools. This new background encouraged academia to explore other issues at stake (such as the new conditions and requirements) rather than diplomatic settings. Such phenomena as the "banalization of summits" (Baigorri 2005:416) ${ }^{2}$, or in Katschinkas's terms «secularization of the profession» (1988:121), the immediate public exposure imposed by press and the blurred boundary between official and off-the-record information, persuaded Baigorri $(2005: 425)$ to advocate research into the relationship between interpreting and political communication.

Perhaps the rigidity, secrecy and difficult access for an outsider that characterise the diplomatic world have also contributed to the scarcity of insights. Finally, another motive for this academic lack of interest might be the fact that DI comprises modalities which overlap with those performed in Dialogue Interpreting (face-to-face interaction in talks between heads of state) or in Conference Interpreting (simultaneous performed at high level multilateral summits or press conferences following diplomatic negotiations or presidential encounters). 
From this point of view, rather than a branch per se, DI would be a hybrid which many scholars might not think of as a separate category.

\section{A TAXONOMIC PROPOSAL FOR ANALYSIS}

A step forward might be the introduction of DI research in postgraduate studies, prompted by the access to interpreted interventions offered by some broadcasters or by the ICT and Social Media. For example, Liao \& Pan (2018:200) use a press conference of Presidents Hu and Obama posted on YouTube by the White House to draw scholarly attention to this type of interpreting. However, in many countries it is performed in simultaneous, which hinders a comparative discourse analysis. On the other hand, the content of high-level talks bound to secrecy (a pillar for research and the main core of DI practice), from which journalists and public are excluded, would be a goldmine for this unexplored area of interpreter-mediated communication. To counter the absence of such data, this taxonomic proposal envisages a wide array of variables for analysis.

One interesting avenue for researchers might be the identification and classification of those aspects DI has in common (although intensified) with other types of interpreting and what makes it different.

In what follows, I propose one such possible insight starting from a threefold classification: a) non-specificity (elements that are common to all types of interpreting but become more critical for diplomatic settings); (b) quasi-specificity (elements which, although shared with other modalities, make primordial reference to DI); c) specificities (encompassing requirements and devices). A schematic version of my taxonomic proposal can be found in Table 1. 


\begin{tabular}{|c|c|c|c|}
\hline \multirow{9}{*}{$\begin{array}{l}\text { Non- } \\
\text { specificity }\end{array}$} & \multirow{2}{*}{\multicolumn{2}{|c|}{ Responsibility }} & Substance \\
\hline & & & Progress \\
\hline & \multirow{2}{*}{\multicolumn{2}{|c|}{ Power }} & $\begin{array}{l}\text { Discursive } \\
\text { Access to knowledge }\end{array}$ \\
\hline & & & Paradiscursive \\
\hline & \multirow{5}{*}{\multicolumn{2}{|c|}{ Stressors }} & Fear to failure \\
\hline & & & Fatigue \\
\hline & & & Interferences \\
\hline & & & Tensions \\
\hline & & & Lack of previous information \\
\hline \multirow{6}{*}{$\begin{array}{l}\text { Quasi- } \\
\text { specificity }\end{array}$} & \multirow{2}{*}{\multicolumn{2}{|c|}{ Role }} & Shared \\
\hline & & & Attached \\
\hline & \multirow{2}{*}{\multicolumn{2}{|c|}{ Ethics }} & Confidentiality \\
\hline & & & Fidelity \\
\hline & \multirow{2}{*}{\multicolumn{2}{|c|}{ Invisibility }} & Etiquette \\
\hline & & & $\begin{array}{l}\text { Choreography } \\
\text { Kinesics/Proxemics }\end{array}$ \\
\hline \multirow{12}{*}{ Specificities } & \multirow{4}{*}{ Requirements } & \multirow{2}{*}{ Situation } & Highly political \\
\hline & & & Sensitive \\
\hline & & \multirow{2}{*}{ Recruitment } & Freelancers \\
\hline & & & Civil servants \\
\hline & \multirow{8}{*}{ Devices } & \multirow{2}{*}{$\begin{array}{l}\text { Coping with } \\
\text { vagueness }\end{array}$} & Understatements \\
\hline & & & Langue du bois \\
\hline & & \multirow{3}{*}{$\begin{array}{l}\text { Coping with } \\
\text { ambiguity }\end{array}$} & Lexical-syntactic \\
\hline & & & Textual \\
\hline & & & Cultural \\
\hline & & \multirow{3}{*}{ Optimisation } & Form \\
\hline & & & Content \\
\hline & & & Process \\
\hline
\end{tabular}

Table 1. Diplomatic Interpreting: taxonomic proposal.

\subsection{Non-specificity of DI: Threats (Responsibility, Power, Stressors)}

It may be that not in every intervention does a diplomatic interpreter contribute "to the history in the making" (Cremona \& Mallia 2001), or to "world harmony" (Delisle 1999:3) but what most professionals and scholars (Fuentes Luque 1999; Reischlová 2012; Buri 2015; Setton \& 
Dawrant 2016) agree upon is the huge responsibility (s)he bears. Weller (2004:36) considers that "the major difficulty associated with diplomatic interpreting lies in the enormous responsibility and pressure the interpreter feels about not making a mistake that could lead to a diplomatic incident". Diplomatic communication, either of a conference type, (more casual, allowing for crisis or disagreements), or of a summit type (more determinant, solutionproviding, interpersonal, face-to-face, usually between the highest representatives of state power) pursue the success of the negotiation which implies both an ability to persuade and to be persuaded, for the sake of progress. From the starting point of Goffman's (1981) participation framework in which sense is continuously negotiated in and by talk, Wadensjö (1995) analyses (in actual interaction in and through talk) the distribution of responsibility which is twofold: for the substance and for the progression of talk. While applicable to all interpreting situations, this view is especially appropriate for DI, where care must be taken of both variables concomitantly: substance not to be modified, and hesitations and longer rephrasing than expected be avoided lest progression is altered, of which the interpreter is instantly informed through non-verbal signals. In turn, Torikai (2009:138-139) envisages responsibility in terms of self-perception (interpreters refraining from making otherwise normal decisions, but which entail a higher risk in DI because of the issues at stake), hence the interpreter's restricted freedom compared to other modalities. One of Torikai's informants recalls interpreting for the President of the Bank of Japan, who "scared her stiff". The interlocutors, MRA officials, needed his support. Thus, when he para-linguistically showed his boredom, the interpreter made her decision. In other circumstances she would have continued interpreting by the rules, but in this case, she interpreted to "keep him interested".

An element which is common in Diplomatic and Community interpreting and thoroughly researched in the realm of the latter is power. While a significant volume of research has been devoted to power as inherent to asymmetrical communicative situations (police officermigrant/refugee; doctor-patient; prosecutor-defendant etc.) in which the interpreter suffers tensions and tries to compensate, approaches to power in diplomatic encounters have been scarce to date. Within frameworks in which communication is set (presumably) between equals, the interpreter wields power by enjoying access to knowledge and as the intermediary in challenging issues that are at stake and upon which, to a certain extent, crucial decisions at a global level might depend. This is explained by Harry Obst in the preface to White House Interpreter. The Art of Interpretation:

Between November of 1985 and May of 1988, one of the most important series of discussions between two men [Reagan-Gorbachev] in all of human history took place. 
At stake were hundreds of billions of dollars and the fate of hundreds of millions of people. The success or failure of these talks would dramatically shape or change the future of many countries in the 1990s and well into the third millennium (Obst 2010:ix).

Presumably symmetrical power relations between orators might be compared to asymmetries characterizing interpreters and other participants at the communicative event in the diplomatic context. Brown \& Levinson's (1987) politeness theory has provided analysis models for all kinds of communicative situations and showed that although courtesy strategies to maintain /reinstate equality between interlocutors are universal, in practice, these strategies are culturally dependant, and that therefore politeness should be approached from a transcultural common ground. However, things are more complicated in diplomatic settings where equality is assumed ${ }^{3}$ as a preliminary condition in protocol norms (attributable to what I call a paradiscursive frame), but as soon as negotiations commence (within the discursive frame) ${ }^{4}$, power relations often become asymmetrical. Like politeness, protocol is universal, but in practice, cultural variables intervene and systematic research into power within highly protocolary mediated interaction appears necessary.

Another common feature with other branches of interpreting, but which in the case of DI is foregrounded, is to be found in the stressor agents among which the literature in the field (Kučerová 1990; Cremona \& Mallia 2001; Reischlová 2012; Zhan 2012; Jiang 2013, Buri 2015) mentions: (1) the fear of failure (the diplomatic interpreter is under permanent scrutiny by the interlocutors, delegates, the cabinet staff, protocol officers or national and international press); (2) fatigue (during sessions which sometimes become unexpectedly lengthy); (3) interferences/diversion agents (especially in consecutive, where interpreters are not insulated from external noise and action); (4) tension and frictions arising in certain negotiations, not only during the process, but even in its aftermath when sometimes interpreters are used as scapegoats and unsolved issues are attributed to misinterpretations ${ }^{5}$. (5) One important stressor (providing specificity to DI) is the lack of previous information, since diplomatic interpreters do not usually have an opportunity to access speeches and background texts beforehand due to secrecy and the need for security. This makes the burden heavier, especially when they are not permanent staff members of the Foreign Ministry or Government department that hires them. Difficulties also arise in introductions and greetings, the interpreter not having had the opportunity to check if any names have been replaced at the last minute. Zhan (2012) mentions the "on-site stress" and shows that in political settings (which he defines as a framework of official meetings on topics related to politics and international 
relations, at which high level officials are involved), the interpreter abides by different norms from other environments.

\subsection{Quasi-specificity of DI: Expectations (Role, Ethics and Invisibility)}

Setton \& Dawrant consider role to be essential, implying precision and personal warmth and most importantly, non-neutrality in those settings (diplomatic, business, military) in which interpreters are typically employed by one side "to which they are expected to provide preferential service in some respects" (2016:377). In general, the interpreter's role is either shared (implying neutrality) or attached (implying exposure and access to confidential matter) and if the latter, the interpreter is accountable to codes of conduct set by the employer (2016:380). However, a recurrent demand by employers is for so-called neutrality, supported by the conduit metaphor adepts and questioned by its detractors (Angelelli 2003). Neutrality seems to be utopian in DI since the interpreter, in many countries, serves one government in high political talks. Zhan (2012) considers this specific face-to-face mode to be far more complex than anything a code of conduct may state. Jiang (2013:212) explains the fact that in DI, each side has its own interpreter because "interpreters are perceived as having clearly defined loyalties". The same point had been made by Pöchhacker (2006:206): "This practice suggests that interpreters in these diplomatic settings work not so much 'between' as 'for' one side or another as members of a given delegation or party". However, neutrality may intervene at a preliminary stage when a diplomatic interpreter has a dilemma on whether to decline or take an assignment in which s/he is likely to convey ideas which are incompatible with her/his own beliefs since, as according to Jiang (2013:212), agreement to undertake a job implies (to varying extents) "siding with the party one interprets for". This point is made by Takeda (2009) or Baker (2006:143-149), who from a narrative theory perspective discusses interpreters' ethical conflicts in situations where a clash with their ideological principles arises. But ideology is not the only reason for refusal; as Freeman (2013) reports, the peril of losing face led him to refuse Nixon's conditions ${ }^{6}$.

In my view, diplomatic interpreters should not be seen as brokers or "co-constructors" of discourse in the way community interpreters often are (Pöchhacker 2008) in light of the contexts of unequal power and diverging interests that sometimes require advocacy or strong mediation. Instead, I share Torikai's (2009) position differentiating between hired professionals who see themselves as "fully trained and prepared not to lose objectivity" and "inner" interpreters-advisors who are often distracted from their main assignment (being asked to perform other tasks simultaneously) which sometimes affects their neutrality. Setton 
\& Dawrant corroborate that there is a wide range of extra services that "affiliated" interpreters are asked to provide (consultancy, advice, analysis), or strategies for their side's benefit (improving cultural appropriateness or persuasiveness), but beyond these conditions, they are ethically bound to provide "default basic fidelity" (2016:380).

Regarding ethics, two aspects are of special concern for DI: confidentiality and fidelity. Confidentiality is common to all interpreting situations, but perhaps in diplomatic settings, discreetness together with a non-censoring, tactful attitude denoting experience and savoir faire are required. A controversial category is memoirs or biographies written by or about great figures in the history of diplomatic interpreting worldwide. Krémer (2016) among others, criticized the decision of some interpreters to reveal aspects of the profession in their memoirs on the grounds that this was an infringement of the confidentiality vow in the code of ethics even when a significant volume of water has flowed under the bridge. The position of the AIIC towards (diplomatic) interpreters writing their memoirs is quite notorious. As Thiéry (1985) warned, confidentiality follows the interpreter "to the grave". But this statement is nuanced by Setton \& Dawrant (2016:342): "However, many such memoirs have been written and today, even many ethically aware people would probably consider that discretion for the same period as the principals themselves and/or as long as the information is officially embargoed, should suffice".

When fidelity is invoked, it is normally intended towards the speaker, in the same way as a translator, but in a rapidly changing, chameleonic style because the interpreter has to be the alter ego of various speakers at one meeting. However, Gile (2009:34) reminds us of the loyalty towards the employer and the recurrent question whether the interpreter can agree to summarize, censor, smooth down if so asked by the client and still practise ethically. In the case of DI for heads of state, the dilemma speaker - client does not apply since the interpreter is hired by the speaker. Setton \& Dawrant (2016:347) discuss this issue in depth and refer to field work which proved that professional interpreters tend to "spontaneously optimize" whereas employers require fidelity and the customary law sanctions interpreters' flexibility. The dilemma arises when employers expect cultural gaps to be bridged and a series of "extended services" to be provided (editing, advising, filling in gaps, saving principal's face, briefing) by the "affiliated" interpreter who turns into a hybrid figure (interpreter cum advisor). Pavel Palazchenko (1990) recalls having been appointed presidential advisor and member of the cabinet by Gorbachov, a reality corroborated by Dobrynin (1995) in the last years of Brezhnev's term. Therefore, one of the ideas challenged by scholars in community and now in diplomatic interpreting (Zhan 2012) is precisely that of "the political interpreter as 
a faithful echo". The "precision" principle (fidelity) is challenged also by Karakoç (2016), who advocates a functionalist approach to DI and explains the causes for "imprecision" based on Nord's (1997) concept of loyalty and Holz-Mänttäri's (1984) triad (commissioner, commission and commissionee). Karakoç argues that deviations in practice do not invalidate norms and sees the diplomatic interpreter as an expert providing intercultural transfer who should not have blind faith in precision.

Invisibility is one of the most enduring metaphors when it comes to the qualities of a good interpreter; one of its many facets is the association between the Kurogo/Kuroco, (the invisible figure in the Kabuki theatre) and the interpreter (Torikai 2009). The diplomatic interpreter must strictly comply with etiquette (dressing appropriately, avoiding conspicuousness, in accordance with the international dress codes but also with those imposed by their own culture) and ensure he/she does not appear in official photographs and TV shots. On the preliminary level, as protocol demands invisibility, a full choreography takes place before the talks actually start, in which the interpreter is shown where to stand for the greetings, for the photographic sessions, for the signing in the book of honour, presentation of official gifts and so on. On the operational level, invisibility does not seem to be an option: the full consecutive mode does not allow interpreters to remain unnoticed. Unlike other interpreting settings, the participation framework in diplomatic interpreting involves many more actors than one expects to take part in the event: security, protocol, communication department, journalists, politicians, cabinet staff, ushers, even physicians - in the case, for instance, of the Spanish Royal House. If the interpreter is one of the staff interpreters of the Language Interpreting Office of the Foreign Ministry, (s)he will know her/his exact position and functions, but an interpreter hired for that occasion (who is an outsider) will lack protocol knowledge and be normally guided by the chief of protocol.

Finally, in what I call choreography, there are two elements, kinesics and proxemics, which are not specific, but can cause certain levels of stress in DI. Poyatos (1994:186) defines kinesics as body movements and positions (conscious or unconscious) which each culture selects as of greater impact. Kinesics offers clues regarding the communicative intention and attitude of the participants in the interaction. In DI, protocol officials are extremely strict in their indications as to where the interpreter should stand or move. On the other hand, proxemics refers to how space is structured and used, and how distances (intimate, personal, social and public) are maintained by communicators since space management marks not only culture but also attitudes. According to Harrigan (2005:149), interactive behaviour is coded by proxemic cues such as: postural identification, distance, frontal orientation and body 
positioning. In DI, proxemics and kinesics are presumably more rigid than in other interpreting settings. If the encounter is a tête-à-tête, the interpreter will probably sit on a chair by his/her speaker's side slightly to the rear. At official dinners, the interpreter will normally stand (or sit) behind the speaker who occupies the seat at mid-table facing the official counterpart guest. The greeting line is one of the most complicated moments especially if it is a welcoming statement on an airport runway, where the interpreter needs to stand closer to the head of state (due to the noise) but is required to remain out of frame and maintain a certain distance.

\subsection{Specificity of DI: Requirements and Devices (Situation and Recruitment; Vagueness/Ambiguity and Optimisation)}

The two features differentiating DI from other interpreting modes are in Xu's opinion (2005:35) the highly political contexts and the great sensitivity of the policies discussed. Ren (2000) cited in Zhan (2012:194) adds two other factors: the low degree of flexibility and the exclusion of personal emotions (since the interpreter represents "national interests"). Indeed, most situations in DI are meetings between leaders, officials or diplomats (where formal consecutive is performed at political talks, negotiations and some press conferences), but also dinners, receptions, ceremonies or site visits at which escort or short informal consecutive, requiring mediation and diplomatic skills, is expected. These situations require that products delivered by diplomatic interpreters should be accurate, complete - as in any other circumstances, but perhaps the differentiating factor is the high-quality expression, as national interest and image are at stake. According to Setton \& Dawrant, specificities of DI comprise special qualities required by the setting - "the delicate choice of words and tone" (2016:1) and the process of recruitment which is carried out among conference interpreters with high performance standards, i.e. accredited freelancers employed by the National Ministry of Foreign Affairs who interpret for their own government, but also junior diplomats with several months in-house training in consecutive (2016:33). Zhan (2012) found that civil servants and embassy staff may be assigned dialogue interpreting in political settings ${ }^{7}$. After analysing six Foreign Affairs meetings at the highest level in the Guangdong Province, Zhan concluded that government staff interpreters were influenced not only by the socio-cultural context of the political dialogue but also by their own political awareness.

On the other hand, diplomatic interpreters develop strategies to cope with vagueness and subtleties and they constantly need to test their own assumptions and the interlocutor's intentions (which may not be revealed from the beginning or may change in the course of the 
discussions). In the words of Ambassador Raimundo Bassols (Baigorri 2014), "when a diplomat says 'yes' he means 'perhaps' and when he says 'perhaps' he means 'no'. When he says 'no' he is no diplomat". In fact, understatement is recognized by many practitioners as the main peril since the real weight of words is much more significant than in everyday speech and interpreters must understand what underlies the unspoken assumptions and the implicit emphasis. Baigorri (2005) starts his discussion from the definition of specialized languages to delve into the nature of political-diplomatic language within its traditional wooden quality (langue de bois) and vagueness, respectively.

Ambiguity (several incompatible meanings coexisting) can be, from a product perspective, lexical-syntactic, textual or cultural; while the first two categories are familiar to all of us, cultural ambiguity is defined as intervening in the way metaphors/idioms are perceived or categorization is performed (how each culture organises environmental features into meaningful clusters: a fiddle, an apple and a canon are the elements describing healthy people in English, Spanish and Romanian). From a process perspective, ambiguity emerges, for instance, in the way an open-ended agreement concluded loosely (no consensus of all parties) is described for press and citizens. On the tightrope, Diplomatic Interpreters keep the fine balance between conveying ambiguities and disambiguating originals. From a Hallidayan (1978:69) perspective of discourse, special attention must be paid both to the historically bound micro-discursive level (linguistic system) and to the culturally bound macro-discursive level (situation). The first comprises lexical shift and fast evolving expressions, for instance terms that were omnipresent some years ago such as superpowers, polarisation, blocs, iron curtain and have been replaced by ethnic cleansing, money laundering, free trade zone, hedge funds, real estate bubble and so on. The interpreter needs to know not just the meaning, but also the origins and historic connotation of such terms and be familiar with the new coinages in both languages since an attempted extempore equivalent is not always acceptable to the counterpart. To adopt new words means to recognize new realities; thus, an interpreter's choice of one or other term in the pair ISIS/DAESH is not trivial, or the change of an expression such as rogue nations into states of concern (to refer to countries such as Iraq, Libya or North Korea) must be recognised not only as a terminological fact but as a political stance too. Although we cannot talk of a technolect in the case of political-diplomatic language, Baigorri (2005:425) warns against its ritualistic dimension, the number of hedges and euphemisms, acronyms, and sometimes even flagrant transgression of courtesy. On the macro-discursive level, tenor ${ }^{8}$ is culturally bound and as such, it might require optimisation defined by Setton \& Dawrant (2016:15) as a set of procedures to bridge cognitive and cultural 
gaps through adjustments to form (rhetorical improvements) or to content (annotations or explanations), or to facilitate or manage the process of communication. An example could be addressing formulae, which constitute an important chapter in diplomatic interpretation. The familiar vocative title in a greeting like Primer Ministro, le agradezco su visita a España (Prime Minister, I thank you for visiting Spain), would require in other languages or rather linguacultures $^{9}$ (Romanian, for instance) a more polite title (Domnule/Doamnă Prim Ministru - Mr./Mrs. Prime Minister) instead.

Optimisation is explained by Setton \& Dawrant (2016:366) as a process entailing risks and benefits which requires expert command of language, knowledge, and intercultural competence. As mentioned above, they distinguish (2016:353) three types of optimisation (form, content and process) that are common to all types of interpreting (except for legal contexts) but acquire special nuances in DI. In optimising, interpreters pursue quality (defined as fidelity to the speaker's communicative intentions plus relevance - maximum cognitive effects through minimal effort). Regarding form (eloquence) which is extremely important in DI, the interpreter presents the speaker's ideas as more interesting, persuasive or memorable and improves the rhetorical impact through style (idiomatic, prosodic or textual features) and other strategies (recapping, rephrasing), whereas content optimisation is related to annotating, editing and explicating and it ranges from indispensable operations to censorship and manipulation. Finally, process optimisation refers to those interventions in communication at a general level (clarifying one's role and procedure, informing of obstacles, drawing attention to ambiguity and providing solutions such as summarizing or abstracting). In turn this kind of optimisation raises problems of visibility. An example of such discursive framing (choosing the third person) is offered by Zhan (2012) who analyses pronoun shifts used by the interpreter in DI in order to a) avoid misunderstandings or impoliteness; b) change the subject (introductions) and c) correct errors. Zhan's conclusion is that the interpreter does not always abide by the rules but performs strong mediation under the constraints of highly charged political settings.

\section{AN EXAMPLE OF OPTIMISATION: ROMANIAN PM'S BLUNDERS}

Although optimisation is a common strategy in interpreting, it is likely to be applied to a greater extent by diplomatic interpreters, especially those affiliated, who filter discourse through omitting, toning down or correcting their party's diplomatic blunders. Recently, Romanian Prime Minister Viorica Dăncilă, on her first visit to Montenegro, at a joint press conference with PM Duško Marković, said she was glad to be in "Pristina", the capital of 
Kosovo (which is not recognized by Romania as a state, hence the unlikelihood of an official visit by a head of government). The interpreter corrected when conveying the PM's words into the Montenegrin version and said Podgorica instead, but as the mode was consecutive, the entire press and international audience clearly heard Pristina. On the Montenegrin TV news, the name of the city was cut from the original, the speech remaining as "I am glad to be at [blank]on the first visit a Romanian Prime Minister..." channels interrupted the live transmission immediately after the city name was uttered. The complete report was deleted from the Government website, but the PM's blunder circulated on social networks. Mrs. Dăncilă's interpreter optimised the product (in her own government's interest, first to save the PM's face and to avoid offending the hosts and secondly because that precise mistake was delicate in the context of former-Yugoslavia countries' configuration). If the blunder had not consisted of a proper name, or had simultaneous been used, such drastic measures by the media would not perhaps have been necessary. In this case, the interpreter's decision is related to content but also to form and process, because optimisation is intrinsically linked to a more general principle: the experienced and qualified interpreter's pursuit of quality. This illustration of how a device that gives specificity to DI within the taxonomic framework that I have proposed as a methodological tool can be analysed is only a grain of sand in an unexplored dune. I trust I have given reasons why DI deserves more extensive research. If it is to be a serious undertaking which I hope it will be, much more empirical evidence is required.

\section{CONCLUSIONS}

This paper has discussed the scarce volume of scientific work in one of the oldest and most decisive types of interpreting, diplomatic interpreting. Starting from observations (such as Mason's 1999) of an imbalanced academic interest in specialities such as diplomatic or business interpreting, I recapitulated a series of possible reasons for this scholarly absence and proposed a methodological tool consisting of a taxonomic frame of elements defining and describing DI. My classification is threefold and comprises: a) non-specificities (threats that are common to all types of interpreting but become more critical for diplomatic settings); (b) quasi-specificities (expectations which, although shared with other modalities make primordial reference to DI); c) specificities (requirements and devices). In the first category I focused on responsibility, power and stressors as common elements, while in the second

\footnotetext{
${ }^{\dagger}$ My translation.
} 
category I chose role, ethics and invisibility as variables with a special role in this type of interpreting. As for the third category, devoted to those factors specific to DI, I tackled some requirements dictated by context and recruitment processes and also some devices, such as vagueness/ambiguity handling or optimisation. The latter was illustrated through a brief analysis of the optimisation performed by the Romanian delegation's interpreter of SerboCroatian and Montenegrin languages in the case of Romanian PM Viorica Dăncilă's recent political blunder at a joint press conference with PM Duško Marković of Montenegro.

In the light of the facts presented, this paper advocates a more systematic and balanced approach to DI, and an exploration of the settings and requirements that make the work of a diplomatic interpreter different from other types of interpreting. Another interesting path would be the investigation of the applicability of such issues to specialised training of interpreters and the inclusion of DI notions in T\&I postgraduate tuition. I hope this paper will open some possible seams of analysis in a speciality so far wrapped in the hermeticism and secrecy which characterise the diplomatic world but which little by little is being disclosed to the public via ICT and Social Media.

\section{Notes}

${ }^{1}$ https://www.calliope-interpreters.org/interpretation-services/executive-interpretation

${ }^{2}$ My translation: "History has never witnessed so many bilateral and multilateral meetings of Heads of State and Ministers occurring on a regular basis in different fora. A certain banalization of summits can be noticed. Due to direct communication and the so-called 'chemistry' between high Government representatives, diplomatic mediation has become redundant."

${ }^{3}$ Protocol requires that high ranking statesmen and women should always use their mother tongue on official occasions but there is a second reason: high level negotiators have always preferred working with interpreters because they gain time to prepare an answer and to observe interlocutors' non-verbal language.

${ }^{4}$ The terms I propose (discursive and para-discursive frames) paraphrase Jiang's (2013: 212) notions of text and paratext borrowed form literary translation to argue diplomatic interpreters' exposure and lack of the shield of paratexts to distance themselves from the principal's position. See also Delisle (1999:3) who warns that "our perception is not entirely independent of the person to whom he lends his voice" and Cronin (2002:394) on 
unfaithfulness as resistance and self-preservation.

${ }^{5}$ See Kumiko Torikai's (2009) discussion of PM Suzuki Kantaro's mokusatsu-suru and the translation error that allegedly provoked the bombing of Hiroshima.

${ }^{6}$ This interpreter disobeyed President Nixon who wanted him to interpret into Chinese (his B language) a reception speech without revealing to him anything related to contents. Nixon refused to show him the written speech which, as later emerged, contained Chinese verses by a cult author which had to be retro-translated into Chinese.

${ }^{7}$ This could also be the Romanian case. On two occasions, when I interpreted for former PMs Rodríguez Zapatero and Rajoy, my counterparts who interpreted for former PM PopescuTăriceanu and President Iohannis were both members of the cabinet staff with a good command of Spanish, but were not interpreters; in fact, being required to do simultaneous for the press conference after the tête à tête came as a surprise.

${ }^{8}$ Halliday \& Matthiessen (2014:705) show that tenor variables are usually discussed in terms of: status, formality, face, tact and politeness

${ }^{9}$ As coined by Friedrich (1989:306) "a domain of experience that fuses and intermingles the vocabulary, many semantic aspects of grammar, and the verbal aspects of culture; both grammar and culture have underlying structure while they are constantly being used and constructed by actual people on the ground. [...] Linguaculture ideology is not about how our ideas of language are determined or at least defined by cultural values, but rather how the complementary processes by which the values implicit in a language determine, define, and affect, a culture"

\section{References}

Angelelli, C. 2003. The visible co-participant: The interpreter's role in doctor-patient encounters. In: Metzger, Collins, M. S. Dively, V. \& Shaw, R. (eds) From Topic Boundaries to Omission: New Research on Interpretation. Washington: Gallaudet University Press. 3-26.

Baigorri, J. 2004. Interpreters at the United Nations. A history. Salamanca: Ediciones Universidad de Salamanca.

Baigorri, J. 2005. Los límites del lenguaje político-diplomático. Un ejemplo del consejo de seguridad de las Naciones Unidas [The limits of political and diplomatic language: an example from the UN Security Council]. In: Romana García, M. L. (ed) Actas del II Congreso Internacional de la Asociación Ibérica de Estudios de Traducción e Interpretación, Madrid 911 de febrero de 2005. Madrid: AIETI. 415-427. Available at: http://www.aieti.eu/wpcontent/uploads/AIETI_2_JBJ_Limites.pdf (accessed 08 August 2019) 
Baigorri, J. 2014. Two Centuries of Diplomatic Interpreting: From Top Hat to Short Sleeves Diplomacy. UNChronicle Vol. 51. No. 3. 44-47. Avaliable at: http://unchronicle.un.org/article/two-centuries-diplomatic-interpreting-top-hat-short-sleevesdiplomacy (accessed 08 August 2019).

Baker, M. 2006. Translation and Conflict: A Narrative Account. London/New York: Routledge.

Baker, M. 2010. Interpreters and Translators in the War Zone. The Translator Vol. 16. No. 2. 197-222.

Baranyai, T. 2011. The Role of Translation and Interpretation in the Diplomatic Communication. SKASE Journal of Translation and Interpretation [online] Vol. 5. No. 2. Available at: http://www.skase.sk/Volumes/JTI06/pdf_doc/01.pdf (accessed 08 August 2019).

Bowen, D., Bowen, M. \& Dobosz, I. 1990. The life of a Diplomatic Interpreter. An Interview with Irena Dobosz. In: Bowen, D. \& Bowen, M. (eds) Interpreting Yesterday, Today and Tomorrow. New York/Tokyo: John Benjamins. 23-33.

Brown L. 2008. The Role of the Political Interpreter in Bilateral Relations: An Overview. MA Thesis. Translation Studies. School of Modern Languages and Translation Studies. University of Tampere. May 2008. Available at: https:/tampub.uta.fi/bitstream/handle/10024/79966/gradu02821.pdf (accessed 08 August 2019).

Brown P. \& Levinson S. 1987. Politeness: Some Universals in Language Use. Studies in interactional sociolinguistics 4. Cambridge: Cambridge University Press.

Buri, M. R. 2015. Interpreting in diplomatic settings. An overview of the challenges faced when accompanying high-level officials and the know-how an interpreter needs to do the job properly. AIIC website. Available at: https://aiic.net/page/7349/interpreting-in-diplomaticsettings/lang/1 (accessed 08 August 2019).

Cremona V.A. \& Mallia H. 2001. Interpretation in Diplomacy. In: Jovan Kurbalija and Hannah Slavik, ed. Language and Diplomacy. Malta: DiploProjects. 301-305. Available at: http://www.diplomacy.edu/resources/books/language-and-diplomacy (accessed 08 August 2019).

Cronin M. 2002. The Empire Talks Back: Orality, Heteronomy and the Cultural Turn in Interpretation Studies. In: Tymoczko, M. \& Gentzler, E. (eds) Translation and Power. Boston/Amherst: University of Massachusetts Press. 387-397. 
Delisle, Jean. 1999. Introduction. In Roland, Ruth (1999): Interpreters as Diplomats. A Diplomatic History of the Role of Interpreters in World Politics. Ottawa: University of Ottawa Press. 1-6.

Dobrynin, A. 1995. In Confidence: Moscow's Ambassador to America's Six Cold War Presidents. New York/Toronto: Random House.

Freeman, C. W., Jr. 2013. Interesting Times: China, America, and the Shifting Balance of Prestige. Charlottesville: Just World Books.

Friedrich, P. 1989. Language, Ideology, and Political Economy. American Anthropologist, New Series Vol. 91. No. 2. 295-312.

Fu, R. \& Chen, J. 2019. Negotiating interpersonal Relations in Chinese-English Diplomatic Interpreting. Interpreting Vol. 21. No. 1. 12-35.

Fuentes Luque, A. 1999. An Approach to Diplomatic Translation. Translation Journal Vol. 3. No. 4. October. Available at: https://translationjournal.net/journal/10dipl.htm (accessed 08 August 2019).

Gile, D. 2000. The History of Research into Conference Interpreting. A Scientometric Approach. Target Vol. 12. No. 2. 297-321.

Gile, D. 2009. Interpreting Studies: A Critical View from Within. MonTI Vol. 1. 135155. Avaliable at: https://rua.ua.es/dspace/bitstream/10045/13040/1/MonTI_01_11.pdf. (accessed 08 August 2019).

Goffman, E. 1981. Forms of talk. Philadelphia: University of Pennsylvania Press.

Halliday, M.A.K. 1978. Language as Social Semiotic. The Social Interpretation of Language and Meaning. London: Edward Arnold.

Halliday, M.A.K. \& Matthiessen, Ch. M.I.M. 2014. Halliday's Introduction to Functional Grammar. $4^{\text {th }}$ edition. London: Routledge.

Hankey, M. 1946. Diplomacy by Conference: Studies in Public Affairs (1920-1946). London: Ernest Benn.

Harrigan, J. A. 2005. Proxemics, Kinesics and Gaze. In: Harrigan, J. A. Rosenthal, R. \& Scherer, K. (eds) The New Handbook of Methods in Nonverbal Behavior Research. Oxford: Oxford University Press. 137-199.

Holz-Mänttäri, J. 1984. Translatorishes handeln. Theorie und methode. Helsinki: Soumalainen Tiede akatemia (Annales Academiæ Scientiarum fennicæ B 226).

Jiang, H. 2013. The ethical positioning of the interpreter. Babel. Vol. 59. No. 2. 209-223. 
Karakoç, N. Y. 2016. Non-cognitive causes of imprecision in consecutive interpreting in diplomatic settings in light of functionalism. Procedia. Social and Behavioral Sciences Vol. 231. 154-158.

Katschinka, L. 1988. Interpreting - the future. In: Picken, C. (ed) ITI Conference 2: Translators and Interpreters mean Business. London: Aslib. 118-125.

Krémer, B. 2016. Another look at professional secrecy. The essence of interpreter ethics can be expressed in a single word: confidentiality. AIIC website. Available at: https:/aiic.net/page/6342/another-look-at-professional-secrecy/lang/1 (accessed 08 August 2019).

Kučerová, H. 1990. Diplomatic interpreting in Czechoslovakia. In: Bowen, D. \& Bowen, M. (eds) Interpreting Yesterday, Today and Tomorrow. New York/Tokyo: John Benjamins, 37-39.

Liao, S. \& Pan, L. 2018. Interpreter Mediation at Political Press Conferences. Interpreting Vol. 20 No. 2. 188-203.

Martin, A. 2003. La direccionalidad y la interpretación: epílogo [Directionality and Interpreting: epilogue]. In: Kelly, D., Martin, A., Nobs, M-L et al. (eds) La direccionalidad en Traducción e Interpretación. Perspectivas teóricas, profesionales y didácticas. Granada: Atrio. 427-434.

Mason, I. 1999. Introduction. In: Mason, I. (ed) Dialogue Interpreting [Special issue]. The Translator Vol. 5. No. 2. 147-160.

Nord, C. 1997. Translating as a purposeful activity: Functionalist approaches explained (Translation Theories Explored). London: Routledge

Obst, H. 2010. White House Interpreter. The Art of Interpretation. Bloomington: AuthorHouse.

Palazchenko, P. 1990. My Years with Gorbachev and Shevardnadze. The Memoir of a Soviet Interpreter. Pennsylvania: The Pennsylvania State University Press.

Pöchhacker, F. 2006. Interpreters and Ideology: From 'Between' to 'Within'. Across Languages and Cultures Vol 7. Nr. 2. 191-207.

Pöchhacker F. 2008. Interpreting as Mediation. In: Valero-Garces, C. \& Martin, A. (eds) Crossing Borders in Community Interpreting: Definitions and Dilemmas. AmsterdamPhiladelphia: John Benjamins. 9-26.

Poyatos, F. 1994. La Comunicación no verbal [Nonverbal communication]. Vol II: Paralenguaje, kinésica e interacción. Madrid: Istmo. 
Prunč, E. 2012. Rights, realities and responsibilities in community interpreting. The Interpreters' Newsletter Vol. 17. 1-12.

Reischlová, D. 2012. Interpreters within the realm of international relations. Role, power, ethical standards and responsibility. MA dissertation. Masaryk University. Available at: https://es.scribd.com/doc/316280839/MA-Thesis-Reischlova-COMPLETE-pdf (accessed 08 August 2019).

Ren, X. 2000. Flexibility of diplomatic interpretation (in Chinese). Chinese Translators Journal 2000 Vol. 3. 35-38.

Roberts, R. 2002. Community Interpreting: A Profession in Search of its Identity. In: Hung, E. (ed) Teaching Translation and Interpreting 4. Building Bridges. Amsterdam: John Benjamins. 157-175.

Setton, R., \& Dawrant, A. 2016. Conference Interpreting. A Complete Course. Amsterdam/Philadelphia: John Benjamins.

Takeda, K. 2009. War and Interpreters. Across Languages and Cultures Vol. 10. No. 1. 49-62.

Thiéry, Ch. 1985. La responsabilité de l'interprète de conference professionnel ou pourquoi nous ne pouvons pas écrire nos mémoires? [The Responsibility of the Professional Conference Interpreter or Why Can we not Write our Memories?]. Meta Vol. 30. No.1. 78-81.

Torikai, K. 2009. Voices of the Invisible Presence. Amsterdam/Philadelphia: John Benjamins.

Wadensjö, C. 1995. Dialogue interpreting and the Distribution of Responsibility. Hermes, Journal of Linguistics Vol. 14. 111-129.

Weller, G. 2004. An Exercise in the Organization of Interpreting Services at High-Level Diplomatic Conferences. The ATA Chronicle. September 2004 Volume XXXIII Number 9. pp36-39

Xu, J. 2005. Training translators in China. Meta Vol. 50. No. 1. 231-249.

Zhan, Ch. 2012. Mediation through personal pronoun shifts in dialogue interpreting of political meetings. Interpreting: International Journal of Research and Practice in Interpreting Vol. 14. No. 2. 192-216. 